\title{
Synthesis of $\boldsymbol{N}$-Benzyl $\mathbf{N}$-Methyl Chitosan by Simultaneous Alkylation of Formaldehyde and Benzaldehyde: Investigation of Chemical Structure and Composition
}

\begin{abstract}
SHAMO ZOKHRAB TAPDIQOV ${ }^{1,2, *}$
'Department of Nanostructured Metal-polymer Catalysist, Azerbaijan National Academy of Sciences, Institute Catalysis and Inorganic Chemistry, Baku, Azerbaijan, H. Javid Avenue.113, AZ1143, Azerbaijan. ${ }^{2}$ Department of Prevention of Sand and Water Appearance, Oil and Gas Research and Design Institute, The State Oil Company of the Azerbaijan Republic, 88a H.Zardabi Avenue, Baku, AZ1012, Azerbaijan.
\end{abstract}

*Corresponding author E-mail: shamo.chem.az@gmail.com

http://dx.doi.org/10.13005/ojc/360206

(Received: February 25, 2020; Accepted: March 26, 2020)

\section{ABSTRACT}

The Schiff base was synthesized by simultaneous reaction of chitosan a natural polyaminosaccharide with formaldehyde and benzaldehyde. The two imine groups formed were then reduced with $\mathrm{NaBH}_{4}$ to give the corresponding tertiary amine derivative. The reaction mechanism and structure of imine intermediate were identified using some spectroscopic methods. The structure, crystallinity degree and molecular electron spectrum of the main product has been characterized by XRD, UV-Vis and ${ }^{1} \mathrm{H},{ }^{13} \mathrm{C}$ NMR analyses. It was observed that, $\mathrm{N}$-benzyl $\mathrm{N}$-methyl chitosan has $14-17 \%$ more crystallinity than chitosan. Inclusion of hydrophobic methyl and benzyl groups into chitosan macromolecule cause reduction in an intermolecular interaction and hydrogen bonding. This leads to an increase in the polarization degree of the product functional groups in a polar environment and better solubility.

Keywords: Chitosan, Schiff base, Alkylation, Arylation, $\mathrm{N}$-benzyl $\mathrm{N}$-methyl chitosan, Solubility.

\section{INTRODUCTION}

Chitosan, a linear cationite natural polyaminosaccharide type is obtained by $\mathrm{N}$-deacetylation of chitin shells of shrimp ${ }^{1-3}$. Chitin is separated from thick rigid shell of some insects, mollusc and especially crustaceans. Chitosan can be considered as a copolymer of chitin and chitosan. The main macromolecular chain consists of $\beta-(1,4)$-2-amino2-deoxy-D-glucosamine and $\beta$-(1,4)-N-acetyl D-glucosamine remnants ${ }^{4-7}$.

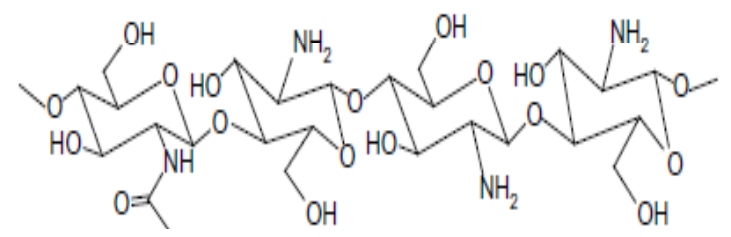

Fig. 1. Structure of chitosan

Depending on deacetylating rate of the amount of free amino groups can be $80-85 \%$. The non-toxicity, biodiversity, biodegradation property

This is an Open Access article licensed under a Creative Commons license: Attribution 4.0 International (CC- BY). Published by Oriental Scientific Publishing Company @ 2018

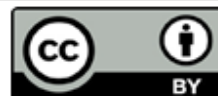


of chitosan stimulate it use for separation control of drugs in medicine and biotechnology and stabilization of antibacterial metal nanoparticles as a carrier and stabilizing matrix ${ }^{8-12}$. Strong hydrogen communication and elctrostatic interaction between the functional groups in chitosan macromolecule prevent its ionization with water molecules. In this regard, lack of water-solubility of chitosan limits its free use. By carrying out chemical modifications on of chitosan macromolecule such as grafting copolymerization, acoustic, alkylating, carboxymethylating, $\mathrm{N}$-phosphonomethylation and etc. New chitosan derivatives which soluble in water or aqueous buffers have been synthesized ${ }^{13-17}$. In terms of molecular structure like modifications can be easy to handle, and small molecule drugs can easily interact by electrostatic or hydrogen bonding. Reaction ability of primary amine, primary alcohol and secondary alcohol groups on chitosan macromolecule are known. Based on this, a large number of new materials can be found by $N$-alkyl and $\mathrm{N}$-arylating, quaternization and obtaining grafting derivatives of chitosan in various studies ${ }^{18-25}$. Muzarelli and Tanfani ${ }^{27}$ have been synthesized risen water and buffer soluble $\mathrm{N}$-trimethyl chitosan chloride by methylation and then quaternization of chitosan with formaldehyde.

In other studies ${ }^{26}$ trimethyl ammonium salt of chitosan was obtained via new method. This method included using dimethyl carbonate as a quaternizing reagent in ionic-liquid environment. Consequently, derivatives, thermal stability and water solubility are more compared to chitosan, were synthesized.

Tommera as developed fluorescent chitosan by synthesizing Schiff base with 9-anthraldehyde subsequently reducing it with sodium cyanoborohydride $^{29}$. The Schiff base intermediates in synthesis of alkylated chitosan themselves enjoy antioxidant activity. Zhu and Guo reported the synthesis of $\mathrm{N}$-arylidene chitosans and during their study were found that the antioxidant activity was equivalent to chitosan 28,30 . The Schiff bases of chitosan could be used to improve the properties of chitosan concerning to the chelation of metal ions, production of analytical reagents for determination of metal ions, preparation of modified electrodes, protection of amino group, et al., Also, chitosanSchiff bases with salicylaldehyde derivatives and new
$N$-(4-pyridilmethylidene) chitosan have been synthesized $^{31}$. The methoxyphenyl aldehydes at vanillin, o-vanillin, syringaldehyde, and veratraldehyde react with chitosan to afford imine derivative, followed by reduction to give the corresponding tertiary amine using standart conditions to impart insolubility and other characteristics to chitosan. The films were obtained from veratraldehyde are insoluble, biodegradable, and mechanically resistant ${ }^{32}$.

It is known that, effective alkyl or arylating of the amino groups of chitosan was carried out by different methods. Inclusion of hydrophobic fragments into chitosan chain increase its antioxidativity and solublility in organic solvents and paralelly changes the thermal properties. In most alkyl or aryl reagents are used in homo form. In our current research, the simultaneous inclusion reaction of both alkyl-methyl and the aryl-benzyl groups into chitosan macromolecule have been studied. The chemical mechanism of the reaction has been studied and the molecular structure has been confirmed by spectroscopic techniques.

In addition surface morphology and thermal stability were determined, molecular structure of main product and intermediate compounds obtained in reaction were characterized by the application of highly sensitive UV-Vis and NMR spectroscopic methods.

\section{MATERIALS AND METHODS}

Chitosan $\mathrm{Mn}=35 \mathrm{kDa}$ (deacetylating degree $85-87 \%$ ), formaldehyde ( $\geq 99.0 \%$ ), benzaldehyde purified by redistillation ( $\geq 99.5 \%$ ), $\mathrm{NaBH}_{4}$ (purum p.a., $\geq 96 \%$ ), glacial acetate acid, ethanol (95\%), acetone (residue analysis, $\geq 99.9 \%$ ), diethyl ether (contains 1 ppm BHT as inhibitor, anhydrous, $\geq 99.7 \%$ ) and the others reagents were purchased from Sigma-Aldrich.

\section{Synthesis of $\boldsymbol{N}$-benzyl $\boldsymbol{N}$-methyl chitosan}

The synthesis of $N$-methyl $N$-benzaldehyde chitosan was achieved in two stages; condensation and reduction. Schiff base derivative has been prepared according to the modified procedure of literture ${ }^{33}$. Chitosan $(1.5 \mathrm{~g})$ is suspended in $\mathrm{CH}_{3} \mathrm{COOH}(60 \mathrm{~mL}, 2 \%)$ solution (containing 7.29 $\mathrm{mmol}-\mathrm{NH}^{2}$ group). Formaldehyde $(0.81 \mathrm{~mL})$ and benzaldehyde $(0.74 \mathrm{~mL})$ mixture is added intensively to the solution in the form of drops of - twice more 
than the equivalent molar ratio. After $30 \mathrm{~min}$ the color of the solution changed from light brown to milky white suspension. The mixture was purged with $\mathrm{N}^{2}$ gas for 4 hours. The solution was then a visco-flowing gel before grinding and waiting for 12 hours. $\mathrm{NaBH}_{4}(0.36 \mathrm{~g})$ was dissolved in water $(8 \mathrm{~mL})$ then added to the solution slowly over 2-4 hours. At that time, the $\mathrm{pH}$ of the solution is contained 4.0-4.5. After $4 \mathrm{~h}$, the $\mathrm{pH}$ of the solution is brought to 10 by added $\mathrm{NaOH}(50 \mathrm{~mL}, 1 \mathrm{M})$, then the gel is formed. The gel was then was washed with distilled water then with ethanol, collapsed in acetone, and extracted with diethyl ether at Soxlet apparatus for 2 days. Then, gel was dried overnight until constant weight at $40-50^{\circ} \mathrm{C}$ after extraction, and freeze dried in vacuo or 24 hours.

\section{Spectroscopic Characterization of $\mathrm{N}$-benzyl $N$-methyl chitosan}

FT-IR spectra of samples were studied in $4000-500 \mathrm{~cm}^{-1}$ area with $4 \mathrm{~cm}^{-1}$ imaging potential with $\mathrm{KBr}$ with its pressed mixtures in the AVATAR 370 (Thermo Nicolet Corporation, USA). X-ray diffractograms of chitosan and reaction products are outlined on the German production Bruker Advance D8 equipment. Diffractograms comprised with $(2 \theta)$ 0.020 imaging scattering rates ranged from 3 to 800 , and scanning speeds $2.0 \mathrm{~min}^{-1}$, accelerated tension

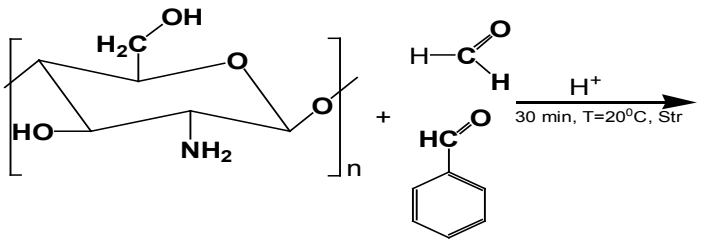

$40 \mathrm{kV}$ and intensity $35 \mathrm{~mA} .{ }^{1} \mathrm{H}$ and ${ }^{13} \mathrm{C}$ NMR spectra of initial polymer, intermediate and final product were outlined at $300.13 \mathrm{MHz}$ and $75.47 \mathrm{MHz} 300 \mathrm{~K}$ on the Bruker Avance 300. Deuteriumized $\mathrm{D}_{2} \mathrm{O}$ and acetatic acid- $d$ were used as solvent. The concentration of samples were taken in the range of $10-25 \mathrm{mg} / \mathrm{mL}$. The UV- Visible analysis of the samples was carried out using UV-Visible Spectrophotometer (Perkin Elmer Lamda-850) the absorbance mode in the wavelength choice of $200-800 \mathrm{~nm}$.

\section{RESULTS AND DISCUSSION}

The exchange of hydrogen atoms from $85-90 \%$ free $-\mathrm{NH}_{2}$ groups on the content of chitosan is commonly found to be substituted by various alkyl and aryl groups based on the Schiff reaction ${ }^{34,35}$. In most cases introducing of alkyl or aryl group into chitosan occur with the addition of the same radicals. Also, the degree of alkylation or arylation of the amine groups ultimately affect the product's solubility and biological properties, which is explained in various ways by the researchers ${ }^{36-38}$. The alkylation and arylation reactions for one protons of amine groups was achieved successfully in our study. Based on FT-IR, ${ }^{1} \mathrm{H},{ }^{13} \mathrm{C}$ NMR, UV-Vis analysis investigations of chitosan, intermediate final product, and the reaction occur on the following mechanism:

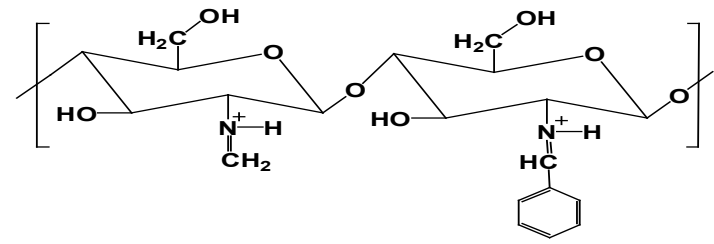

Scheme 1. The initialy intermediate product structure of chitosan with formaldehyde and benzaldehyde

The presence of a chromophore group in the final product shows itself in the color of the substance as well as in the formation of a characteristic peak of the $-\mathrm{HC}=\mathrm{N}^{+} \mathrm{H}$ - double bond in the spectrum of 1640

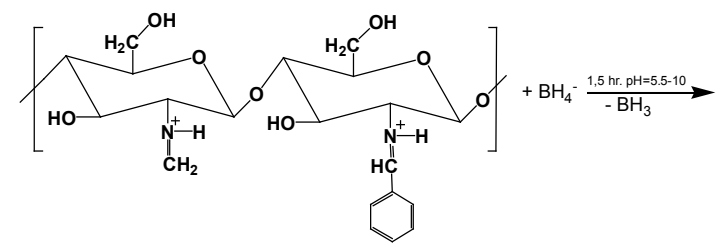

Scheme 2.Reduction of quaternized N-benzyl N'-methyl chitosan

Depending on the mole ratio of the reaction components, concentration and nature of aldehyde, the average molecular weight of the chitosan and the $\mathrm{cm}^{-1}$. The peak which belongs to this Shift is not observed in the spectrum of chitosan. After a certain period of time, the change in the color of the solution depends on the following equilibrium process.

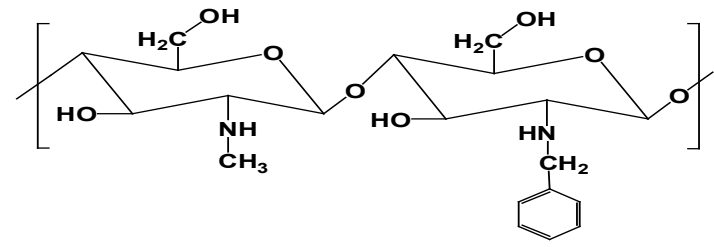

reaction time the gel formation occurs in different forms ${ }^{39,40}$. It has been determined that, complete replacement of amine groups does not occur in 
chitosan. Moreover, acetoamide groups in the composition could not be replaced by alkyl or aryl groups. Taking this into consideration, structure of the final product can be shown as follows:

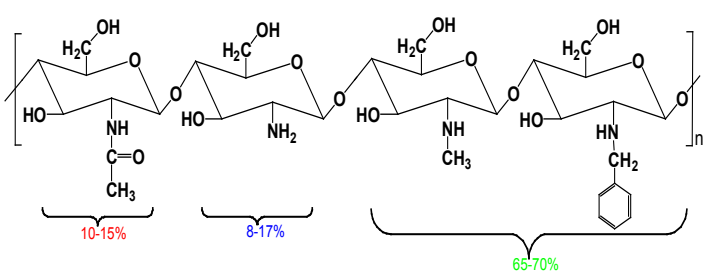

Fig. 2. Supposed structural composition of $\mathrm{N}$-benzyl $N$-methyl chitosan

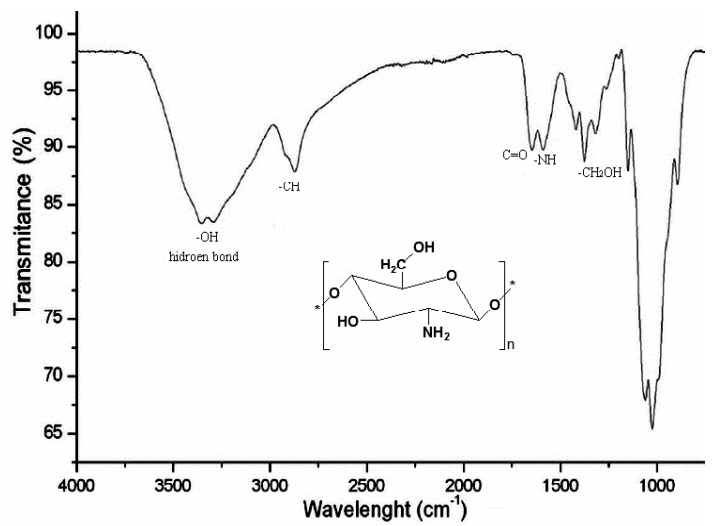

Fig. 3. The FT-IR spectrum of chitosan and $N$-benzyl $N$-methyl chitosan

The peak at $1657 \mathrm{~cm}^{-1}$ was assigned to the axial stretching of $>\mathrm{C}=\mathrm{O}$ bonds of the acetamide groups, referred to as amide I band. The peak at 1571 is belong to angular deformation of $-\mathrm{NH}_{2}$ group. $1260 \mathrm{~cm}^{-1}$ (bending vibration of C-N band) match with the chitosan groups involved in the chemical modification. The observed peaks at $3478 \mathrm{~cm}^{-1}$ is belong to tightened vibrations of $-\mathrm{OH}$ and $-\mathrm{NH}_{2}$ groups. After alkylation, the peaks $1592-$ $1598 \mathrm{~cm}^{-1}$ belonging to adsorption strip of the $\mathrm{N}-\mathrm{H}$ bond disappeared, which proves the exchange of protons as a result of methyl or benzyl. Additionally, intensive peaks in the 2875 and $1457 \mathrm{~cm}^{-1}$ region are increasing as compared to chitosan, which corresponds to the asymmetric stretch and bending of $\mathrm{C}-\mathrm{H}$ bond. The presence of the benzene ring in macromolecule could be proved it according to 4 absorption peak basically in the $2000-1400 \mathrm{~cm}^{-1}$ range. $\mathrm{C}=\mathrm{C}$ bond oscillation of the benzene ring in $\mathrm{N}$-benzyl $\mathrm{N}$-methyl chitosan demonstrate 1583 $\mathrm{cm}^{-1}, 1466 \mathrm{~cm}^{-1}$ combined frequencies and oberton absorption strips. On the other hand, if benzene ring is considered as mono replacement state, benzene rings in $900-650 \mathrm{~cm}^{-1}$ area has a strong absorption as a result of deformation oscillations of $\mathrm{C}-\mathrm{H}$ bonds.
After alkylation, FT-IR spectra of product and initial polymer were investigated comparatively. The absorption peak belonging to the polysaccharide groups in the spectrum of the chitosan and $N$-benzyl $N$ '-methyl chitosan groups (C-O-C vibration of asymmetric stretching) in 1157 $\mathrm{cm}^{-1}$, the peaks characterizing II and I alcohol groups $1422 \mathrm{~cm}^{-1}$ and $1378 \mathrm{~cm}^{-1}$, as well as 1087 and $1032 \mathrm{~cm}^{-1}$ bond shifts (the deformation of C-O bond), are the same ${ }^{28,29}$. This shows that, there is no any chemical changes that have occurred in these groups.

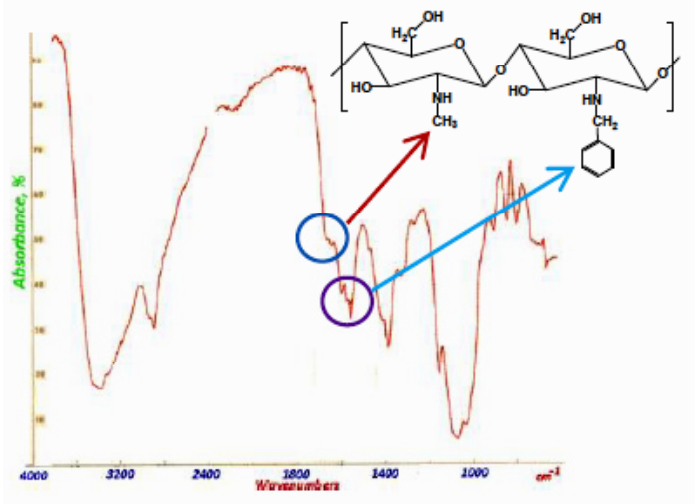

Such a replacement characteristrics in the product appears in 760 and $675 \mathrm{~cm}^{-1}$ adsorbtion area ${ }^{41}$.

The reaction mechanism and molecular structure of product was studied by the UV-Vis electron spectra was performed. It was determined besides the chitosan, and the reduced chitosan derivatives were a very poor solubility in water. Highly sensitive method has been used in the discovery of the molecular structure of these polymer modifications. The analysis of samples has been studied in the ultraviolet region due to slight solubility. Taking this into account, their solutions were prepared $(0.01-0.001 \%)$ and electron spectra of them were monitored (Figure 4).

In the content of initial polysaccharidechitosan spectrum, a broad peak around $208 \mathrm{~nm}$ was observed, which belongs to the non-deacetylating fragment of the carbodiimide functional group $>\mathrm{C}=\mathrm{O}$. With inclusion alkyl and aryl fragment the structural variation occurs in the polymer chains. This shows itself in the form of a spectrum and in the formation of the second absorption band in the $225-240 \mathrm{~nm}$. Thus, the second intensive peak at the high wavelength 
is characteristic to the $>\mathrm{C}=\mathrm{N}$ - chromophore group (also benzene ring) or $\mathrm{n} \rightarrow \pi^{*}$ transition in it. The breakdown of $\pi$ bond after reduction affects the electron density of the macromolecule and the characteristic strip of the chromophore group disappears. This proves that the alkylation reaction occurs consistently, and the intermediate carbocation product forms a major mass during the reaction. Also, the electron nature of the $>\mathrm{C}=\mathrm{O}$ group in the deacetylated chitin residue disrupts due to alkaline substitution occurring in the chitosan macromolecule within or between macromolecules that affects the nature of the electrostatic interactions. As a result, his proves that the characteristic peak belonging to this passage is exposed to the chemical sliding with a bathochromic shift.

The exact molecular structure of the derivatives from the reaction and the presence of the functional groups were studied using the ${ }^{1} \mathrm{H}$ and ${ }^{13} \mathrm{C}$ NMR spectroscopies. In the following Figure, the ${ }^{1} \mathrm{H}$ NMR spectrum of chitosan and the final products $N$-benzyl $N$ '-methyl chitosan and the signals of corresponding peaks are given.

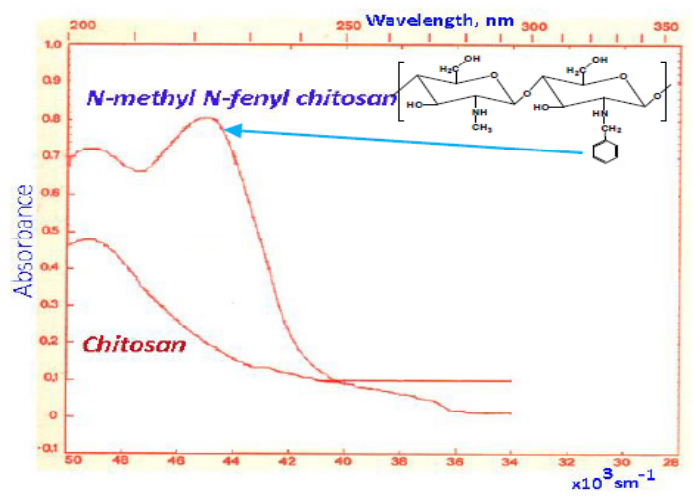

Fig. 4. The UV-Vis spectrum of chitosan and $N$-benzyl $N$-methyl chitosan

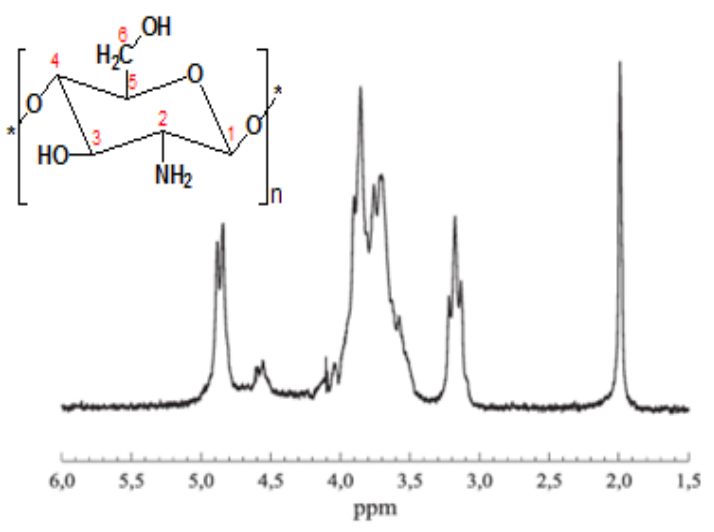

Fig. 5. The ${ }^{1} \mathrm{H}$ NMR spectrum of chitosan
As the reaction proceeds gradually, ${ }^{1} \mathrm{NMR}$ spectra of intermediate products were analyzed and signals of protons and carbons which exposed to basic chemical shifts were registered.

The ${ }^{1} \mathrm{H}$ and ${ }^{13} \mathrm{C}$ NMR spectra of chitosan: (300 MHz, $\mathrm{D}_{2} \mathrm{O} / \mathrm{d}$-acetic acid); $2.08(2 \mathrm{H}), 2.12(1 \mathrm{H})$, $1.98(1 \mathrm{H}), 4.81(1 \mathrm{H}), 3.18(1 \mathrm{H}), 3.79(1 \mathrm{H}), 3.28$ $(4 \mathrm{H}), 4.06(5 \mathrm{H}), 3.63(2 \mathrm{H}) .{ }^{13} \mathrm{C}$ NMR $(300 \mathrm{MHz}$, $\mathrm{D}_{2} \mathrm{O} / \mathrm{d}$-acetic acid); 102.3, 53.4, 68.2, 72.1, 72.6, 59.1. Reduction of the imine bond led to disappear the color due to replace the chromophore group with auxochrome groups. Changes are observed in the common view of the spectrum and in the chemical shift of signals. Because of the exchange of the proton in the amine group with the methyl and benzyl groups, new chemical signals appear ${ }^{42}$.

The ${ }^{1} \mathrm{H}$ and ${ }^{13} \mathrm{C}$ NMR spectrum of $\mathrm{N}$-benzyl $\mathrm{N}$-methyl chitosan shows weak and strong signals at 7.85 and 2.12 belong to the phenyl ring and $\mathrm{NH}$ imine respectively. Hydrogens attached to $\mathrm{NH}$ in the methyl group are observed at the intermediate 2.38 ppm ortho position protons for the phenyl ring were seen at $7.09 \mathrm{ppm}$, meta protons $7.22 \mathrm{ppm}$, while para protons appear at $6.98 \mathrm{ppm}$ with weak signals respectively.

${ }^{13} \mathrm{C}$ NMR spectrum shows a characteristic signals at $171.2 \mathrm{ppm}$ belong to the carbonyl group, and signal at $128.7 \mathrm{ppm}$ is attributed to the phenyl ring. A signal at $31.9 \mathrm{ppm}$ is for $\mathrm{CH}_{3}$ of the acetyl group, and a signal at $1.37 \mathrm{ppm}$, which attributed to the aliphatic carbon. Chemical signals in other carbons are identic to chitosan. The chemical signals of the $\mathrm{CH}_{3}$ and $\mathrm{CH}$ groups at phenyl ring prove that alkylation occurs. When taking aldehyde more than the equimolar ratio (2-4 times) during the reaction, the alkylation occurs deeper. After reductions with $\mathrm{NaBH}_{4}$, the product becomes colorless, it means that the $>\mathrm{C}=\mathrm{N}$ chromophore bond is reduced and a new view appears in the ${ }^{1} \mathrm{H}$ and ${ }^{13} \mathrm{C}$ NMR spectra. A detailed comparison of NMR results indicates that alkylation of chitosan with formaldehyde and benzaldehyde has been occurred chemically. Meanwhile, the analysis of intermediate products indicates that the process is chemically effective ${ }^{43,44}$.

It is known that, some crystalline phase could be observed in the chitosan macromolecule, which is essentially amorphous. Also, the chemical 
modification of the polymer macromolecule such as the conjunction of alkyl or aryl groups and conversion to a salt form affects its crystallinity. For this purpose,

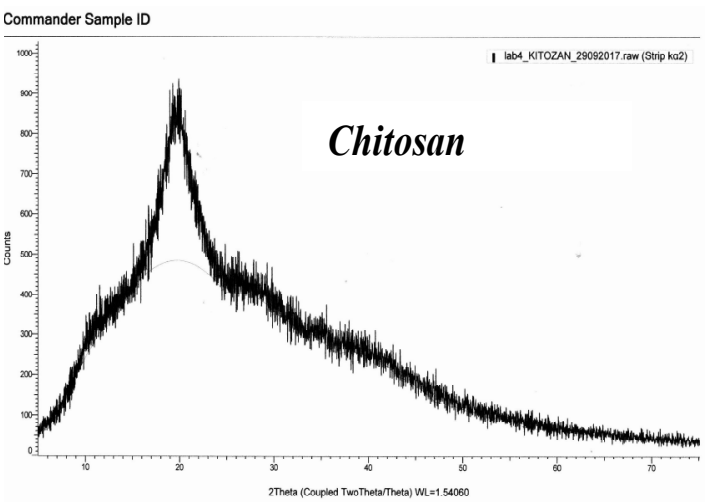

X-ray diffractograms of chitosan and $N$-benzyl $N$-methyl chitosan were investigated and the results were given in the following Figure.

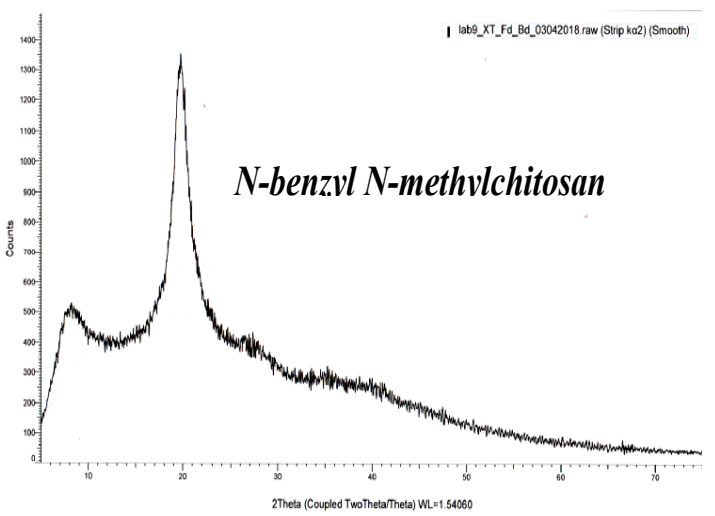

Fig. 6. X-ray diffractograms of chitosan and $N$-benzyl $N$-methylchitosan

The two diffraction peaks at $2 \theta=10^{\circ}$ and $19.7^{\circ}$ levels for the chitosan characterized by the crystal domains are shown in the Fig. 6. Which, these crystalline phases have been formed due to the hydrogen bonding between amine groups. In $N$-benzyl $N$-methyl chitosan diffractogram, the peaks are clearly visible. The inclusion of methyl and benzyl groups into chitosan macromolecule leads to an increase of crystallinity up to $28-29 \%$. Also, absence of characteristic peaks for hydrogen bond proves that the protons at amine group were exposed to the alkylation and arylation ${ }^{45}$.

$N$-benzyl N-methyl chitosan has an ability to dissolve in water and in a certain $\mathrm{pH}$ range, in contrast to the free polymer. Whereas the solubility of the chitosan is made up $2-3 \%$, its methyl and benzyl derivative have a solubility of $65-78 \%$. Also, chitosan is well-soluble in the $\mathrm{pH}=1-5$ range, and precipitates in $\mathrm{pH}=8-12$. In the obtained product, he functional groups produce intensive absorption in the solution, which are soluble in $\mathrm{pH}=1-10$ range. The degree of solubility depends on the amount of aldehyde during the reaction ${ }^{46-47}$. It has been found that the best solubility of $N$-benzyl $N$-methyl chitosan is optimum, when the content of methyl and benzyl groups totally $60-70 \%$. The $N$-aryl substituted trimethyl chitosan obtained by the reductive alkylation and quaternization sequence such as quaternized $\mathrm{N}$-(4-methylbenzyl) chitosan, $N$-(4-N,N-dimethylaminobenzyl) chitosan and quaternized $N$-(4-pyridylmethyl) chitosan have also been prepared and tested for antibacterial activities.
These substituents did not impart increase in the antibacterial activity of chitosan backbone48. From these derivatives, quaternized $N-(4-N, N-$ dimethylaminobenzyl) chitosan was investigated for the transfection efficiency using the plasmid DNA encoding green fluorescent protein pEGFPC2 on human hepatoma cell lines (Huh7 cells), in comparison to trimethyl chitosan and chitosan ${ }^{49}$. The results indicated that the improved gene transfection was due to the hydrophobic group on chitosan, which promoted the interaction and condensation with DNA, as well as $N$-quaternization has increased the water solubility. Spectroscopic and thermal analyzes show that after alkylation, the product maintains its basic physical and biological properties characteristic to the chitosan. This allows it to be used in the process of delivery and controlled release of some antibiotics and proteins ${ }^{50}$.

\section{CONCLUSION}

The inclusion of hydrophobic methyl and benzyl groups into chitosan macromolecule leads to change of chemical properties. Thus, solubility of non-water chitosan with methyl and benzyl groups of Schiff bases and their reductions products increases 20-23 times in the water environment and at $\mathrm{pH}=6$ 10 buffers. Simultaneous inclusion of alkyl and aryl groups in macromolecule increases both crystallinity of chitosan up to $22 \%$. As it is known, interaction of soluble chitosan derivatives with drugs and enzymes becomes easier and such type of matrices can be used as a carrier or storage in medicine. 


\section{ACKNOWLEDGEMENT}

The author acknowledges the Science Foundation of "The State Oil Company of the Azerbaijan Republic" (SOCAR), for financial support of the research activities related to project;
Grant project 33LR-SOCAR/ANAS.

\section{Conflicts of interest}

There is not any conflict of interest including any financial, personal or other relationships with other people or organizations.

\section{REFERENCES}

1. Prio, S.; Chairil, A.; Jumina, D.S.; Suharso and Keisuke, Ohto.; Orient. J. Chem., 2018, 34, 30-37.

2. Yang, J.; Tian, F.; Wang, Z.; Wang, Q.; Zeng, Y.J.; Biomed. Mater. Res., 2008, 84, 131-137.

3. Yen, M;.T.; Yang, J.H.; Mau, J. L.; Carbohydr. Polym., 2008, 74, 840-844.

4. Sheeba, J.B.S.; Subhashini, S.; Asian Journal of Chemistry., 2018, 30, 1469-1475.

5. Muzzarelli, R.A.A; Guerrieri, M.; Goteri, G.; Muzzarelli, C.; Armen, T.; Biomaterials., 2005, 26, 5844-5854.

6. Rinaudo, M.; Chitin and chitosan., 2006, 31, 603-632.

7. Arti, V.; Sharif, A.; Orient. J. Chem., 2013, 29, 861-870.

8. Patrulea, V.; Ostafe, V.; Borchard, G.; Jordan, O.; Eur. J.Pharmaceutics and Biopharmaceutics., 2015, 97, 417-426.

9. Tapdiqov, Sh.Z.; Zeynalov, N.A.; Humbatova, S.F.; J.Chem. Chemical Eng., 2014, 8, 800-804.

10. Matthew, B.A.; Mc, Cullough.; Mark, Gomes.; Jagannathan, S.; Orthopaedics., 2017, 8, 15.

11. Paolicelli, P.; De La Fuente, M.; Sánchez, A.; Seijo, B.; Drug Deliv., 2009, 6, 239-253.

12. Tapdiqov, Sh.Z.; Zeynalov, N.A.; Taghiyev, D.B.; Digest J.Nanomat.and Biostr., 2016, 10, 39-44.

13. Kurita, K.; Polymer Degradation and Stability., 1998, 59, 117-120.

14. Chatelet, C.; Damour, O.; Domard, A.; Biomaterials., 2001, 22, 261-268.

15. Kurita, K.; Mori, S.; Nishiyama, Y.; Harata, M.; Polymer Bulletin., 2002, 48, 159-166.

16. Tapdigov, Sh.Z.; Safaraliyeva, S.F.; Theato, P.; Zeynalov, N.A.; Tagiyev, D.B.; Raucci M.G.; Hasanova, M.X.; J. of Biomimetics, Biomaterials and Biomedical Engineering., 2018, 39, 77-88.

17. Amri, S.; Indriana, K.; Deni, P.; Lisna, J.M.; Orient. J. Chem., 2017, 33, 3003-3008.

18. Tien, C.L.; Lacroix, M.; Ispas-Szabo, P.; Mateescu, M.A.; J.Controlled Release., 2003, 93, 1-13.
19. Kurita, K.; Sugita, K.; Kodaira, N.; Hirakawa, M.;Biomacromolecules., 2005, 6, 14141418.

20. Kim, K.; Thomas, R.; Lee, C.; Park, H.; J. Food Protect., 2003, 66, 1495-1498.

21. Zong, Z.; Kimura, Y.; Takahashi, M.; Yamane, H.; Polymer, 2000, 41, 899-906.

22. Sahariah, P.; Benediktssdottir, B.E.; Hjalmarsdottir, M.A.; Biomacromolecules, 2015, 16, 1449-1460.

23. Maingam, K.; Colloid Surf., 2006, 49, 117-125.

24. Tanuma, H.; Saito, T.; Nishikawa, K.; Dong, T.; Carbohydr. Polym., 2010, 80, 260-265.

25. Zhang, C.; Ding, Y.; Yu, L.; Ping, Q.; Colloid Surf., 2007, 55, 192-199.

26. Benediktsdottir, B.E.; Baldursson, O.; Masson, M.; J. of Controlled Release., 2014, 173, 18-31.

27. Muzzarelli, R.A.A.; Tanfani, F.; Carbohydr. Polym., 1985, 5, 297-307.

28. Meiyan, Wu.; Zhu, Long.; Huining, Xiao.; Cuihua, Dong.; Carbohydr. Polym., 2017, 169, 83-91.

29. Tommeraas, K.; Strand, S.P.; Tian, W.; Kenne, L.; Carbohydr. Res., 2001, 336, 291-296.

30. Guo, Z.; Xing, R.; Liu, S.; Yu, H.; Wang, P.; Bioorg. Med. Chem. Lett., 2005, 15, 4600-4603.

31. Guinesi, L.S.; Cavalheiro, E.T.G.; Carbohydr. Polym., 2006, 65, 557-561.

32. Guinesi, L.S.; Cavalheiro, E.T.G.; Thermochim. Acta., 2006, 449, 1-7.

33. Rodrigues, C.A.; Laranjeira, M.C.; Stadler, E.; Dragod, V.; Carbohydr. Polym., 2000, 42, 311-320.

34. Muzzarelli, R.A.A.; Ilari, P.; Carbohydr. Polym., 1994, 23, 155-160.

35. Don, T.M.; King, C.F.; Chiu, W.Y.; J.Appl Polym Sci., 2002, 86, 3057-3063.

36. Liu, Y.; Liu, Z.; Zhang, Y.; Deng, K. J.; Appl Polym Sci., 2003, 84, 2283-2289.

37. Chen, C.Y.; Chen, C.C.; Chung, Y.C.; Bioresour. Technol., 2007, 98, 2578-2583.

38. Wu, Y.; Dong, Y.; Zhou, F.; Ruan, Y.; Wang, H.; Zhao, Y.; Appl. Polym. Sci., 2003, 90, 583-586. 
39. Mansouri, S.; Cuie, Y.; Winnik, F.; Shi, Q.; Lavigne, P.; Biomaterials., 2006, 27, 2060-2065.

40. Obara, K.; Ishihara, M.; Ishizuka, T.; Fujita, M.; Biomaterials., 2003, 24, 3437-3444.

41. Zhu A., Zhang M., Shen J., Biomater J. Sci. Polym. Ed., 2003, 14, 411-421.

42. Tantayanon S., Tangpasuthadol V., Thatte M., William H. D, Biological Macromolecules., 2008, 43, 79-87.

43. Sajomsang,W.; Tantayanon, S.; Tangpasuthadol, V.; Carbohydr Res., 2009, 14, 2502-2511.

44. Radhakumary, C.; Divya, G.; Nair, P.D.; Mathew, S.; J. Sci. Appl. Chem., 2003, 407, 715-730.

45. Caner, H.; Yilmaz, E.; Yilmaz, O.; Carbohydr.
Polym., 2007, 69, 318-325.

46. Said, S.E.; Khalid, D.Kh.; Maher, Z.E.; J App Poly Sci., 2006, 99, 3308-3317.

47. Hasipoglu, H.N.;Yilmaz, E.;Yilmaz, O.; Caner, H.; Int.J.Polym.Anal.Charact., 2005, 10, 313327.

48. Sajomsang, W.; Tantayanon, S.; Tangpasuthadol, V.; Carbohydr. Polym., 2008, 72, 740-750.

49. Rojanarata, T.; Petchsangsai, M.; Opanasopit, P.; T.; Eur.J.Pharm. Biopharm., 2008, 70, 207214.

50. Tapdiqov, Sh.Z.; Zeynalov, N.A.; Humbatova, S.F.; Nagiev, J.A.;Asian J. Chemistry., 2015, 28, 189-193. 